\title{
Isolation, Cloning and Co-Expression of Lipase and Foldase Genes of Burkholderia territorii GP3 from Mount Papandayan Soil
}

\author{
Ludwinardo Putra ${ }^{1}$, Griselda Herman Natadiputri ${ }^{2}$, Anja Meryandini ${ }^{1}$, and Antonius Suwanto ${ }^{1,2 *}$ \\ ${ }^{1}$ Graduate School of Biotechnology, Bogor Agricultural University, Bogor 16680, Indonesia \\ ${ }^{2}$ Biotechnology Research and Development, PT Wilmar Benih Indonesia, Bekasi 17530, Indonesia
}

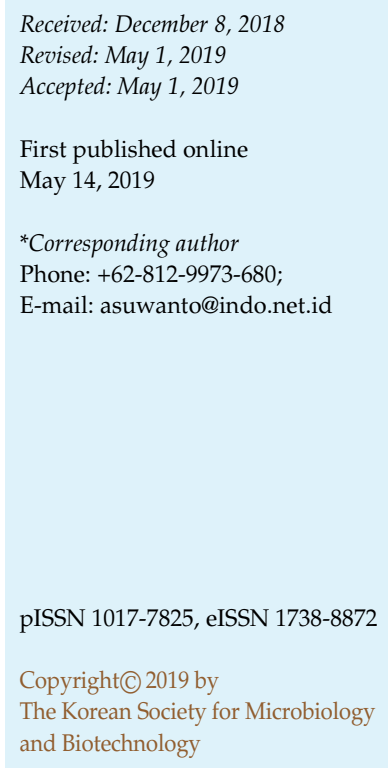

\begin{abstract}
Lipases are industrial enzymes that catalyze both triglyceride hydrolysis and ester synthesis. The overexpression of lipase genes is considered one of the best approaches to increase the enzymatic production for industrial applications. Subfamily I.2. lipases require a chaperone or foldase in order to become a fully-activated enzyme. The goal of this research was to isolate, clone, and co-express genes that encode lipase and foldase from Burkholderia territorii GP3, a lipolytic bacterial isolate obtained from Mount Papandayan soil via growth on Soil Extract Rhodamine Agar. Genes that encode for lipase (lipBT) and foldase (lifBT) were successfully cloned from this isolate and co-expressed in the E. coli BL21 background. The highest expression was shown in E. coli BL21 (DE3) pLysS, using pET15b expression vector. LipBT was particulary unique as it showed highest activity with optimum temperature of $80^{\circ} \mathrm{C}$ at $\mathrm{pH}$ 11.0. The optimum substrate for enzyme activity was $C_{10}$, which is highly stable in methanol solvent. The enzyme was strongly activated by $\mathrm{Ca}^{2+}, \mathrm{Mg}^{2+}$, and strongly inhibited by $\mathrm{Fe}^{2+}$ and $\mathrm{Zn}^{2+}$. In addition, the enzyme was stable and compatible in non-ionic surfactant, and was strongly incompatible in ionic surfactant.
\end{abstract}

Keywords: Burkholderia territorii GP3, E. coli BL21 (DE3) pLysS , foldase, lipase

\section{Introduction}

Lipases are enzymes that catalyze both the hydrolysis of triglycerides and synthesis of ester. This widely used enzyme group plays many roles in industrial applications, such as in the manufacturing of detergent formulation, biodiesel, and ester flavoring, as well as in bioremediation [1]. Lipases from Burkholderiaceae, such as Burkholderia and Ralstonia, are known for their potential for industrial applications, due to their high resistance to the solvent methanol and their high alkalinity [2]. By those characteristics, this lipase group could become a potential catalyst for biodiesel production by transesterification reaction [3].

Lipase-encoding genes are typically cloned and overexpressed for their applications in industry, particularly to ensure purity and high yield. There were several reports of lipase gene expression in different systems [2, 4, 5]. In particular, lipases from Burkholderia spp., which belong to subfamilies I.2, require a folding protein (foldase) in order to be actively expressed. In members of this genus, the foldase-encoding gene (lif) was clustered with a lipaseencoding gene as an operon [6].

Two strategies for co-expression of lipase and foldase may be employed, including in vitro and in vivo folding. In in vitro folding, the lipase- and foldase-encoding genes are expressed in different hosts and vectors. Co-expression occurs as they are combined together in the same reaction, resulting in fully active lipase [7]. In in vivo folding, the lipase- and foldase- encoding genes are expressed in the same host, using either a two-plasmid or a one-plasmid system. The two-plasmid system involves the isolation and expression of both genes in separate vectors. On the other hand, the one-plasmid system requires only one plasmid for expression, as the lipase- and foldase-encoding genes are expressed together as one operon [8].

Genes that encode for lipase were successfully isolated from Burkholderia spp. and expressed in a different system, mostly in homologous hosts [2, 4]. Recently, the lipase- 
encoding gene from Burkholderia contaminans was successfully expressed in a heterologous host for the first time [5]. The expression occured in a two-plasmid system and thus far, there is no report for heterologous expression in a oneplasmid system. In this work, the co-expression of genes that encode for lipase and foldase genes from Burkholderia territorii GP3 was done in a one-plasmid system for heterologous expression. Moreover, we found that the expressed lipase demonstrates a unique characteristic, showing high activity even at $80^{\circ} \mathrm{C}$, while other Burkholderiaderived lipases mostly showed their optimal activity at $70^{\circ} \mathrm{C}$.

In this study, we isolated and cloned the lipase- and foldase-encoding genes from Burkholderia territorii GP3 and co-expressed both genes in the Escherichia coli BL21 background. The enzyme was further characterized to define its uniqueness for further industrial application.

\section{Materials and Methods}

\section{Materials}

The pGEM-T Easy and pET-15b vectors were purchased from Promega (USA) and Novagen (USA), respectively. Escherichia coli $\mathrm{DH} 5 \alpha$ and E. coli DH10 $\beta$ were obtained from the lab culture collection and used as cloning hosts. The expression hosts, E. coli BL21 (DE3) (pLysS) and E. coli Origami B, were purchased from Takara (Japan). E. coli SHuffle B and SHuffle K were purchased from NEB (USA). All restriction enzymes and T4 DNA ligase used in this study were purchased from NEB. All $\rho$-nitrophenyl synthetic substrates were purchased from Sigma-Aldrich (USA).

\section{Bacterial Isolation and Identification}

Soil samples were collected from Mount Papandayan and enriched with livestock fat enrichment for 30 days. The soil was serially diluted, then incubated for $48-72 \mathrm{~h}$ at $30^{\circ} \mathrm{C}$ on Soil Extract Rhodamine Agar, which contained filtered-soil extract (500 g/l) as base media, bacto agar (1.5 g/l), PVA, olive oil (4\%), Rhodamine B $(0.1 \%)$. The medium was adjusted to $\mathrm{pH}=3.0$ using $0.2 \mathrm{M}$ citratephosphate buffer. Lipolytic bacteria that showed a clear zone around their colonies were incubated for $24 \mathrm{~h}$ at $30^{\circ} \mathrm{C}$ on Luria Agar (yeast extract $5 \mathrm{~g} / \mathrm{l} ; \mathrm{NaCl} 10 \mathrm{~g} / \mathrm{l}$, tryptone $10 \mathrm{~g} / \mathrm{l}$; bacto agar $15 \mathrm{~g} / \mathrm{l})$. The isolate was identified based on $16 \mathrm{~S}$ rDNA using universal primer pairs for bacteria [9]. Sequence analysis was done using the 16S rRNA identification tools at www.ezbiocloud.net.

\section{Amplification and Cloning of LipBT and LifBT}

Genes that encode for lipase (lipBT) and foldase (lifBT) in Burkholderia territorii were jointly amplified as an operon using a modified primer pair [4]. The operon was cloned into pGEM-T Easy vector, using E. coli $\mathrm{DH} 5 \alpha$ as a host. Recombinant E. coli colonies were verified using colony PCR and further grown on
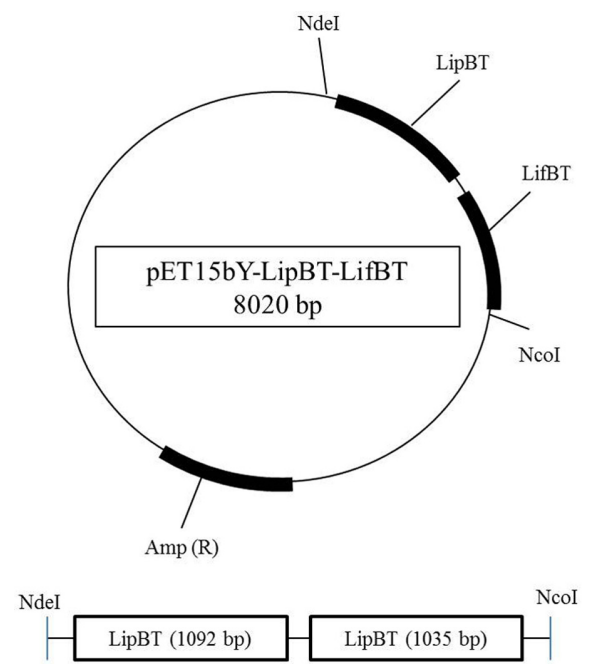

Fig. 1. Plasmid map of $\mathrm{pET}-15 \mathrm{~b}+\mathrm{LipBT}+\mathrm{LifBT}$ recombinant vector.

The plasmid contains ampicillin resistance gene as selection marker, along with NdeI and NcoI restriction site.

Rhodamine Agar supplemented with ampicilin $(100 \mu \mathrm{g} / \mathrm{ml})$. LipBT- and LifBT-encoding gene sequences were analyzed using Geneious 11.0.5 and VMD 1.9.3 [10, 11]. The operon was further cloned into pET15b with some modification at the multiple cloning site (pET-15b). The operon was cloned into pET-15b at the NdeI and NotI site (Fig. 1). Recombinant pET-15b was transformed to E. coli DH10ß using the heat shock method [12].

\section{Amino Acid Analysis and Protein Modeling of LipBT}

The amino acid analysis was carried out by Geneious 11.0.5. Alignment of LipBT and LifBT was achieved using BLAST. The secondary structure of each protein sample was predicted using the Predict Secondary Structure application from Geneious 11.0.5 [10]. Prediction of disulfide bonding of LipBT was carried out by DISULFIND [13]. The protein model of LipBT was acquired as PDB using SWISS-MODEL, and visualized by VMD [11, 14]. Quality assessment of the protein model was carried out by ProQ3 with the embedded CAD and LDDT scores [15].

\section{Co-Expression of LipBT and LifBT}

LipBT and LifBT were co-expressed in pGEM-T Easy and pET$15 \mathrm{~b}$ plasmids in a variety of hosts, including E. coli DH5 $\alpha$, E. coli DH10ß, E. coli BL21 (DE3) pLysS, E. coli Origami B, E. coli SHuffle B, and E. coli SHuffle K. Seed culture for each host was prepared on $10 \mathrm{ml}$ Luria Broth supplemented with appropriate antibiotics (100 $\mu \mathrm{g} / \mathrm{ml}$ ampicillin or, $30 \mu \mathrm{g} / \mathrm{ml}$ chloramphenicol) at $37^{\circ} \mathrm{C}$ and $200 \mathrm{rpm}$ overnight. Seed culture (1\%) was inoculated onto $50 \mathrm{ml}$ Luria Broth supplemented with appropriate antibiotics and grown in the same conditions up to OD600 $\approx 0.5$ and $0.25 \mathrm{mM}$ IPTG was subsequently added into the culture, followed by further incubation at $37^{\circ} \mathrm{C}$ and $200 \mathrm{rpm}$ for $16 \mathrm{~h}$. Bacterial cells 
were harvested by centrifugation at 7,000 $\times g, 4^{\circ} \mathrm{C}$ for $10 \mathrm{~min}$, and suspended in $5 \mathrm{ml}$ Tris- $\mathrm{HCl} 0.1 \mathrm{M} \mathrm{pH}$. The cells were lysed using Handy Sonic ur-21p sonicator for $15 \mathrm{~min}$, and centrifuged at $11,000 \times g, 4^{\circ} \mathrm{C}$ for $15 \mathrm{~min}$. The supernatant was collected as cellfree extract and used in further enzymatic assays.

Lipase activity was measured using spectrophotometry method based on hydrolysis using $\rho$-nitrophenyl ester as substrates [16]. Reaction mixture was composed of $940 \mu \mathrm{l}$ Tris- $\mathrm{HCl} 0,1 \mathrm{M} \mathrm{pH} 8$, $40 \mu \mathrm{l}$ absolute ethanol, $10 \mu \mathrm{l} \rho$-nitrophenyl ester substrate, and $10 \mu \mathrm{l}$ cell-free extract. The mixture was incubated at $40^{\circ} \mathrm{C}$ for $5 \mathrm{~min}$. The concentration of the hydrolysis product, $\rho$-nitrophenol (pNP) was measured using a spectrophotometer at $405 \mathrm{~nm}$. One unit of lipase was defined as the amount of lipases required to release $1 \mu \mathrm{mol}$ of pNP under the specific condition mentioned.

\section{Lipase Purification}

Lipase produced by specific host carrying an expression vector with the highest lipase activity was partially purified using ammonium sulfate partial precipitation. The precipitation was done in five steps, resulting in five fractions of saturated ammonium sulfate: $<20 \%, 20-30 \%, 30-40 \%, 40-50 \%$, and $>50 \%$. Each fraction was collected and dialyzed for $16 \mathrm{~h}$. The lipasespecific activity of each fraction was quantified and compared as described above. The fraction showing the highest specific activity was used for characterization. Furthermore, SDS-PAGE on 10\% $(\mathrm{w} / \mathrm{v})$ SDS polyacrylamide gels and zymography were used to determine the molecular masses of LipBT and LifBT. In this case, we did not perform heating before loading the samples for zymogram analysis. Zymogram was performed by incubating the gel in Tris-Cl pH 8 buffer for $20 \mathrm{~min}$.

\section{Characterization of LipBT}

Purified LipBT activities in varying temperature and $\mathrm{pH}$ were evaluated using the lipase assay described above. The effect of temperature was determined within the range of $10-90^{\circ} \mathrm{C}$. To test for LipBT thermostability, the protein was incubated at $10-80^{\circ} \mathrm{C}$ for $30 \mathrm{~min}$ in Tris- $\mathrm{HCl} 0.1 \mathrm{M}, \mathrm{pH}$. The effect of $\mathrm{pH}$ was determined within the range of 3.0 to 13.0 . For $\mathrm{pH}$ stability, LipBT was incubated at $40^{\circ} \mathrm{C}$ for $30 \mathrm{~min}$ at $\mathrm{pH} 3.0$ to 13.0. The reactions were carried out on the following buffers $(0.1 \mathrm{M})$ : citrate buffer ( $\mathrm{pH} 3.0$ to 5.0), phosphate buffer ( $\mathrm{pH} 5.0$ to 7.0), Tris- $\mathrm{HCl}$ buffer ( $\mathrm{pH} 7.0$ to 9.0), and glycine-NaOH buffer ( $\mathrm{pH} 9.0$ to 13.0).

Substrate specifity of LipBT was determined towards $\rho$-nitrophenyl substrates with various ester chains, including $\rho$-nitrophenyl $\mathrm{C}_{4}, \mathrm{C}_{8}, \mathrm{C}_{10}, \mathrm{C}_{12}, \mathrm{C}_{14}, \mathrm{C}_{16}$, and $\mathrm{C}_{18}$. Hydrolysis activity towards $\rho$-nitrophenyl $C_{4}, C_{8}, C_{10}$ was measured using spectrophotometry method. A different assay method was used for $\rho$-nitrophenyl $\mathrm{C}_{12}, \mathrm{C}_{14}, \mathrm{C}_{16}$, and $\mathrm{C}_{18}$. About $20 \mu \mathrm{l}$ lipase was added to $880 \mu \mathrm{l}$ of reaction buffer containing $50 \mathrm{mM}$ Tris- $\mathrm{HCl}(\mathrm{pH} \mathrm{8.0)}$, $0.1 \%$ gum arabic, and $0.2 \%$ deoxycholate. After incubation at $30^{\circ} \mathrm{C}$ for $3 \mathrm{~min}$, the reaction was started by addition of $100 \mu \mathrm{l}$ substrate $8 \mathrm{mM}$ (in isopropanol) and incubated at $30^{\circ} \mathrm{C}$ for $3 \mathrm{~min}$. The reaction was stopped by addition of $0.5 \mathrm{ml}$ of $3 \mathrm{M} \mathrm{HCl}$. The mixture was centrifugated at $12,000 \times g$ for $2 \mathrm{~min}$, then $333 \mu \mathrm{l}$ supernatant was mixed with $1 \mathrm{ml}$ of $2 \mathrm{M} \mathrm{NaOH}$. The OD was measured at $420 \mathrm{~nm}$.

The effect of various organic solvents, metal ions and surfactants on LipBT stability was evaluated by incubating purified lipase at $40^{\circ} \mathrm{C}$ for $30 \mathrm{~min}$ in the presence of the following substances: organic solvent, methanol, ethanol, butanol, ispropanol, acetonitrile, and n-hexane (50\%); metal ions, $\mathrm{CaCl}_{2}, \mathrm{MgCl}_{2}, \mathrm{CuCl}_{2}, \mathrm{ZnCl}_{2}$, and $\mathrm{FeCl}_{2}(0.1 \mathrm{M})$; surfactants, DMSO, Triton $\mathrm{X}-100$, Tween-80, and sodium dodecylsulfonate (SDS) (1\%). As for control, the lipase was incubated in buffer Tris- $\mathrm{HCl} \mathrm{pH}$ 8.0. Following that, lipase activities were measured at $80^{\circ} \mathrm{C}, \mathrm{pH} 11.0$ for $5 \mathrm{~min}$.

\section{Results and Discussions}

\section{Bacterial Isolation and Identification}

Soil Extract Agar is a bacterial isolation medium that contains limited nutrients, micro-nutrients that cannot be found in other nutrient-rich media [17]. In this study, we used a combination of Rhodamine Agar and Soil Extract Agar as the base medium, instead of Luria Bertani. Such modification may increase the possibilities of growing lipolytic bacteria that are previously non-culturable. Five bacterial colonies were succesfully isolated on Soil Extract Rhodamine Agar. Among them, isolate GP3 was the only one that showed lipolytic activity. Upon growth on Rhodamine Agar for approximately 5 days, the color of GP3 colonies changed from orange to green, and then later turned gray. In contrast, the color of bacterial colonies on In Luria Agar shifted from yellow to purple. Such a shift in colony pigmentation was not observed on Soil Extract Rhodamine Agar, in which the bacterial colonies remained pink throughout the incubation period. Aside from the possibility of pigment degradation due to bacterial death, such pigmentation variability might be caused by difference in the media composition and growth conditions, such as $\mathrm{pH}$ and temperature [18].

Based on the 16S rDRNA analysis, isolate GP3 shared the highest similarity with Burkholderia territorii LMG25818 (99.69\%), followed by Burkholderia cepacia ATCC 25416 (99.61\%), Burkholderia anthina R-4183 (99.61\%), Burkholderia seminalis R-24196 (99.53\%), and Burkholderia metallica R-16017 (99.45\%). Burkholderia territorii LMG25818 was originally isolated from soil in Papua New Guinea soil and considered as a novel bacterium [19]. While it possessed lipolytic activity, to date there is no report on B. territorii lipaseencoding gene isolation and expression from the species. Thus far, only the lipase-encoding genes from Burkholderia contaminans and Bukrholderia cepacia have been successfully isolated and expressed $[4,5]$. 




Fig. 2. Amino acid alignment and secondary protein structure prediction of LipBT with related lipase from Burkholderia contaminans LTEB11, Burkholderia cepacia G63, and Burkholderia cepacia ATCC 25416.

The purple bars represented $\alpha$-helix structure, and the yellow arrows represent $\beta$-sheet. The diagram describes how amino acid sequence showed differences in the secondary structure formation.

\section{Cloning and Amino Acid Analysis of LipBT}

The B. territorii GP3 lipase operon is $2,312 \mathrm{bp}$ in length, and is composed of the $1,092 \mathrm{bp} \alpha / \beta$ hydrolase-encoding gene (lipBT), and the 1,035 bp of the lipase foldase-encoding gene (lifBT) (Fig. 1). Both genes were regulated by the T7 constitutive promoter from pGEM-T Easy. Both of lipBT
A

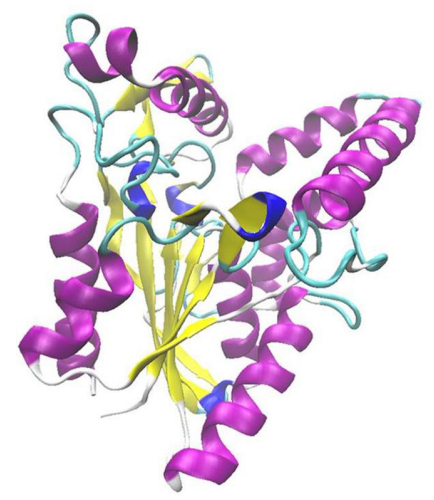

B

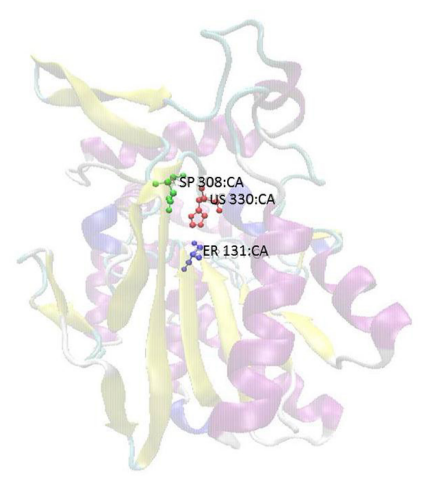

Fig. 3. Predicted protein structure of LipBT.

(A) 3D structure of LipBT. $\alpha$-helix and $\beta$-sheet structure are marked in purple and yellow respectively; (B) predicted catalytic triad (SerAsp-His) of LipBT. Ser ${ }_{131}$ (ER 131:CA), Asp ${ }_{308}$ (SP 308:CA), and $\mathrm{His}_{330}$ (US 330:CA) are marked as purple, green, and red, respectively.

and lifBT were closely related to the lipase- and foldaseencoding genes in B. cepacia INT3-BP177 (99.0\%), B. cenocepacia ZYB002 (98.6\%), Burkholderia sp. SIB005 (98.6\%), B. cepacia FDAARGOS_388 (98.2\%), and B. cepacia ATCC25416 (98.2\%). The amino acid identity among LipBT and corresponding proteins in B. cepacia ATCC25416, B. contaminans LTEB11, and B. cepacia $\mathrm{G} 63$ was $97.0 \%, 97.0 \%$, and $91.5 \%$, respectively. As for LifBT, it showed the same identity percentage.

The protein modeling was constructed, along with the model consistency. The model with a CAD score of 0.865 and LDDT score of 0.732 (which indicates the right folding of protein) was chosen for analysis [15]. LipBT consisted of 364 amino acids, including 40 amino acids that were predicted as signal peptide. It carried the conserved pentapeptide G-X1-S-X2-G, as X1 and X2 stands for His and Glu, respectively (Fig. 2). Its catalytic triads were identified as Ser131, Asp308, and His330, located in the coil structure of the protein (Fig. 3). Two cysteine residues, Cys234 and Cys314, were predicted to form disulfide bonding, resulting in formation of a disulfide bridge, as in Burkholderia lipases [13]. Amino acid alignment among LipBT and the other Burkholderia lipases revealed the presence of 17 non-conserved amino acid residues. As these amino acids cause the difference in the length and formation of secondary structures, there is no evidence that these could determine the characteristics of the lipase activity.

\section{Co-Expression and Partial Purification of LipBT}

LipBT and LifBT were co-expressed as an operon in both 
Table 1. Lipase activity of LipBT expressed in various vectors and Escherichia coli hosts.

\begin{tabular}{llc}
\hline \multicolumn{1}{c}{ Vectors } & \multicolumn{1}{c}{ Hosts } & Lipase activity $(\mathrm{U} / \mathrm{mg})$ \\
\hline pGEM-T Easy & DH5 $\alpha$ & $0.08 \pm 0.01$ \\
pET-15b & DH10 $\beta$ & $0.11 \pm 0.02$ \\
& BL21 (DE3) pLysS & $6.73 \pm 0.24$ \\
& Origami B & $0.41 \pm 0.05$ \\
& SHuffle B & $0.19 \pm 0.02$ \\
& SHuffle K & $0.16 \pm 0.01$ \\
\hline
\end{tabular}

The hydrolytic activity was measured at $40^{\circ} \mathrm{C}, \mathrm{pH} 8.0$ for $5 \mathrm{~min}$.

pGEM-T Easy and pET-15b. E. coli DH5 $\alpha$ was used as host for pGEM-T Easy recombinant vector, while E. coli DH10 $\beta$, BL21 (DE3) pLysS, Origami B, SHuffle B, and SHuffle K were used as host for recombinant pET-15b. Lipase activity was measured from cell-free extracts of these host and vector combinations. E. coli BL21(DE3) pLysS expressing pET-15b+LipBT+LifBT showed the highest lipase activity (6.73 U/mg) (Table 1). Both SHuffle B and SHuffle K have the similar activity, while Origami B is slightly higher. In comparison, lipase activities derived from both the pGEM$\mathrm{T}$ Easy and pET-15b background were similar. Our data indicate that expression host selection has more effect on increasing lipase activity than vector selection. In this case, E. coli BL21 (DE3) pLysS is the best expression host. Lysozyme S, encoded in the pLysS plasmid, can decrease basal protein expression, thus leading to higher activity of lipase [20]. Thus, lipase produced in the E. coli BL21 (DE3) pLysS and pET-15b background was used for further purification and characterization.

LipBT was partially purified using ammonium sulfate precipitation. The process consisted of four steps and resulted in five fractions of purified lipase $(<20 \%, 20-30 \%$, $30-40 \%, 40-50 \%$, and $>50 \%$ ). Fraction $20-30 \%$ showed the highest specific activity $(15.88 \mathrm{U} / \mathrm{mg})$, while fraction $<20 \%$

Table 2. Specific activity of ammonium sulfate precipitation fractions for LipBT purification.

\begin{tabular}{lccc}
\hline Fraction & $\begin{array}{c}\text { Lipase activity } \\
(\mathrm{U} / \mathrm{ml})\end{array}$ & $\begin{array}{c}\text { Protein } \\
\text { concentration } \\
(\mathrm{mg} / \mathrm{ml})\end{array}$ & $\begin{array}{c}\text { Specific activity } \\
(\mathrm{U} / \mathrm{mg})\end{array}$ \\
\hline$<20 \%$ & 0.19 & 0.20 & 0.85 \\
$20-30 \%$ & 16.45 & 1.04 & 15.88 \\
$30-40 \%$ & 12.51 & 1.17 & 10.66 \\
$40-50 \%$ & 8.31 & 1.48 & 5.61 \\
$>50 \%$ & 0.08 & 0.31 & 0.26 \\
\hline
\end{tabular}

The hydrolytic activity was measured at $40^{\circ} \mathrm{C}, \mathrm{pH} 8.0$ for $5 \mathrm{~min}$.

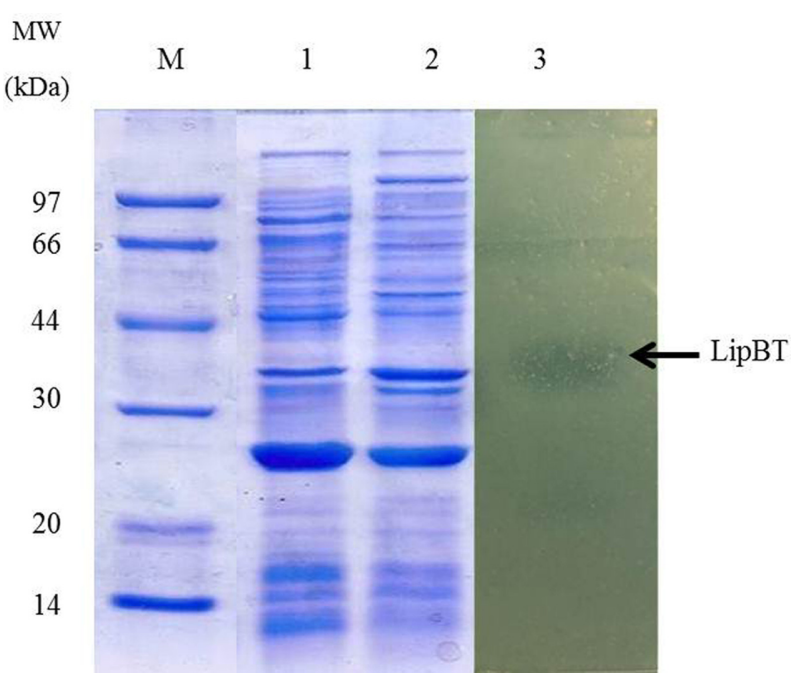

Fig. 4. SDS-PAGE and zymography of LipBT.

Lane M: low-range ladder; lane 1: pET-15b(-); lane 2: purified LipBT (20-30\% fraction); lane 3: zymogram of purified LipBT.

and $>50 \%$ showed the lowest activity (Table 2 ). SDS-PAGE results showed that the molecular mass of LipBT was around $30 \mathrm{kDa}$ (Fig. 4).

\section{Characterization of LipBT}

LipBT was characterized based on spectrophotometry and analyzed as relative or residual activity [21]. The optimal temperature of LipBT was $80^{\circ} \mathrm{C}$ (Fig. 5), in contrast to lipases from other Burkholderia spp. that showed optimal activity at temperatures around $40-70^{\circ} \mathrm{C}[4,5,22,23]$. LipBT was thermally stable at $10-40^{\circ} \mathrm{C}$, in which high residual activity of the enzyme was observed following $30 \mathrm{~min}$ incubation at said temperature $(>80 \%)$. Similarly, other Burkholderia spp. lipases showed low stability at higher temperature $\left(>50^{\circ} \mathrm{C}\right)$. It was suggested that the thermal stability of this enzyme is hypothesized to be mainly determined by the formation of a disulfide bond among its cysteine residues [24].

LipBT was most optimal at $\mathrm{pH} 11.0$, and it was stable at pH 5-11 (Fig. 6). Most Burkholderia lipases are considered as alkaline enzymes, since they are highly active and stable in an alkaline environment $(\mathrm{pH}>8.0)$ [25]. For example, Burkholderia cepacia ATCC 25416 and Burkholderia contaminans LTEB11 lipases showed optimum activity at $\mathrm{pH} 11.0$ and 8.0 , respectively $[4,5]$. To date, there has not yet been any report on lipases that work in acidic conditions from Burkholderia spp. As an alkaline enzyme, LipBT may potentially be used in biodiesel production and as a detergent additive [26]. 
A

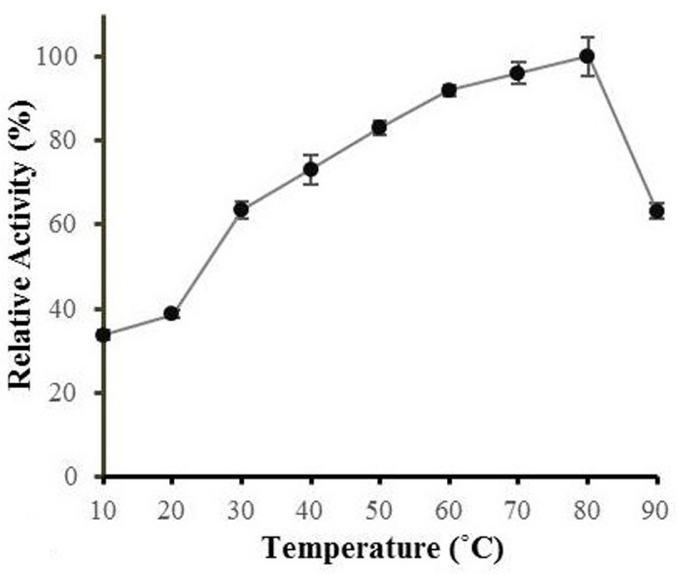

B

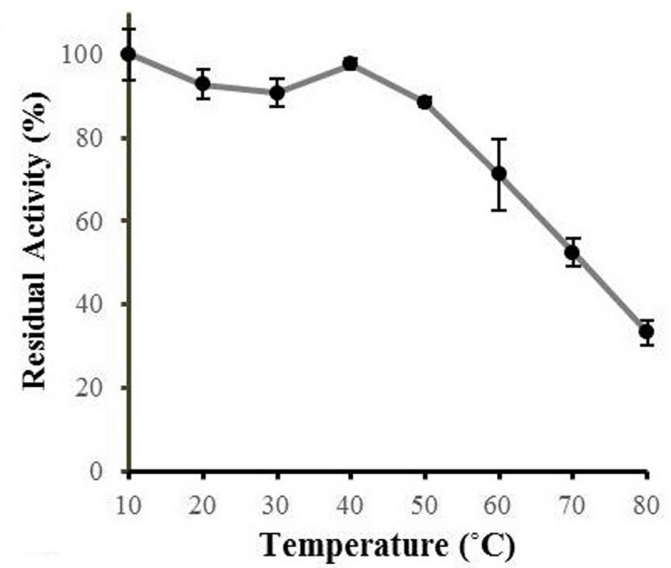

Fig. 5. Effect of temperature on the activity and stability of LipBT.

(A) Optimum temperature of LipBT at $\mathrm{pH} 8.0$. The $100 \%$ relative activity represented an enzyme activity of $19.35 \mathrm{U} / \mathrm{mg}$; (B) Thermostability of LipBT after incubation for $30 \mathrm{~min}$ at $\mathrm{pH} 8.0$ in various temperatures. The thermostability was measured at $80^{\circ} \mathrm{C}, \mathrm{pH} 8.0$. The $100 \%$ relative activity represented an enzyme activity of $18.22 \mathrm{U} / \mathrm{mg}$.

Various $\rho$-nitrophenyl compounds with various ester chain lengths $\left(\mathrm{C}_{4}-\mathrm{C}_{18}\right)$ were employed to assess the substrate specifity of LipBT (Table 3). LipBT shows the highest activity for $\mathrm{C}_{10}$ and the lowest activity for $\mathrm{C}_{4}$. The same characteristic was reported in other Burkholderia lipases, in which they showed preferences for substrates containing long ester chains [4]. To our knowledge, there has not yet been any report for Burkholderia lipase with optimum activity against substrates with short ester chains. The structure and motifs on oxyanion holes have played a crucial role in determining substrate preferences [27].

LipBT was highly stable in the presence of alcohol solvents, such as methanol, ethanol, isopropanol, buthanol, and acetonitrile (Table 4). In the presence of alkaline
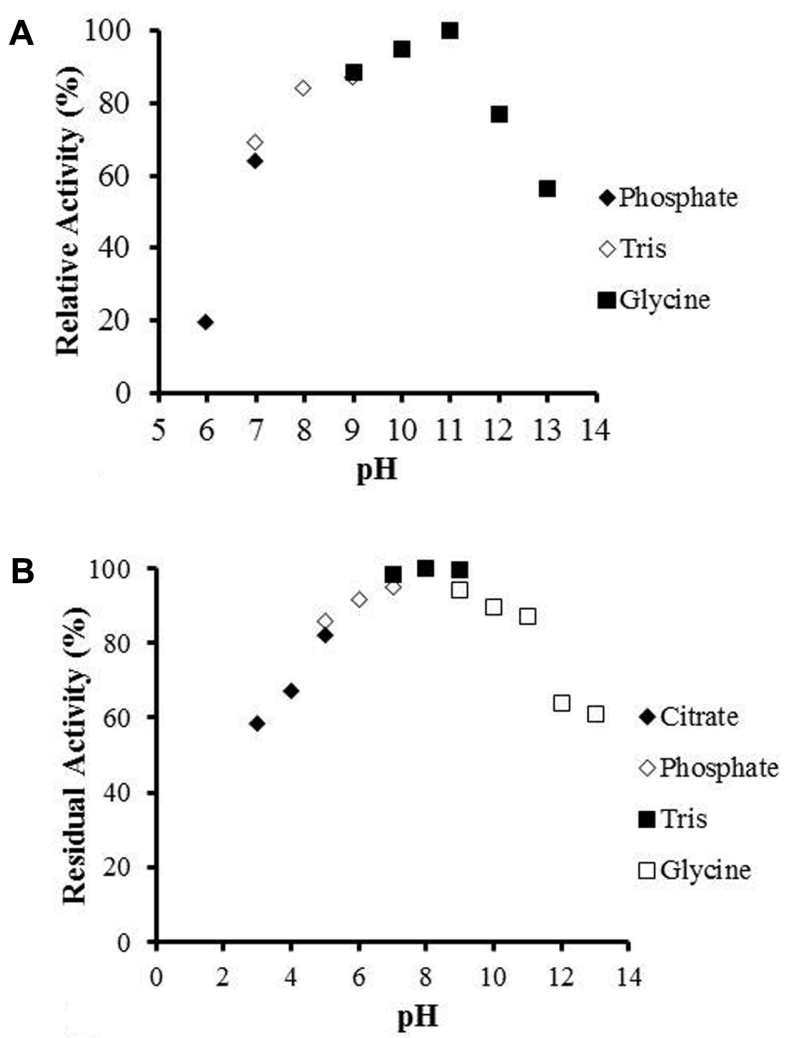

Fig. 6. Effect of $\mathrm{pH}$ on the activity and stability of LipBT.

(A) Optimum $\mathrm{pH}$ of LipBT at $80^{\circ} \mathrm{C}$. The $100 \%$ relative activity represented an enzyme activity of $22.41 \mathrm{U} / \mathrm{mg}$; (B) The $\mathrm{pH}$ stability of LipBT after incubation for $30 \mathrm{~min}$ at $40^{\circ} \mathrm{C}$ in various $\mathrm{pH}$. The $\mathrm{pH}$ stability was measured at $80^{\circ} \mathrm{C}, \mathrm{pH} 11$. The $100 \%$ residual activity represented an enzyme activity of $20.67 \mathrm{U} / \mathrm{mg}$.

solvents, LipBT was highly stable and slightly activated, and its residual activity was $>100$. Most Burkholderia lipases are highly stable in methanol, which makes them potential catalyzers for transesterification in biodiesel production [2].

The effect of metal ions on LipBT activity was examined

Table 3. Substrate specifity of LipBT at $80^{\circ} \mathrm{C}, \mathrm{pH} 11.0$.

\begin{tabular}{cc}
\hline$\rho$-Nitrophenyl substrate & Relative activity $(\%)$ \\
\hline $\mathrm{C}_{4}$ & 28.12 \\
$\mathrm{C}_{8}$ & 77.57 \\
$\mathrm{C}_{10}$ & 100.00 \\
$\mathrm{C}_{12}$ & 92.96 \\
$\mathrm{C}_{14}$ & 79.15 \\
$\mathrm{C}_{16}$ & 86.75 \\
$\mathrm{C}_{18}$ & 54.81 \\
\hline
\end{tabular}

The $100 \%$ relative activity represented an enzyme activity of $21.59 \mathrm{U} / \mathrm{mg}$. 
Table 4. Effect of organic solvents on LipBT stability after incubation for $30 \mathrm{~min}$ at $40^{\circ} \mathrm{C}, \mathrm{pH} 8.0$.

\begin{tabular}{lc}
\hline Solvent & Residual activity $(\%)$ \\
\hline Control & 100.0 \\
Methanol & 94.9 \\
Ethanol & 82.8 \\
Butanol & 78.0 \\
Isopropanol & 77.8 \\
Acetonitrile & 85.0 \\
n-Hexane & 120.1 \\
\hline
\end{tabular}

Enzymatic activity was measured at $80^{\circ} \mathrm{C}, \mathrm{pH} 11.0$. The $100 \%$ residual activity represented an enzyme activity of $20.59 \mathrm{U} / \mathrm{mg}$.

by incubating purified enzyme in various ions. $\mathrm{Ca}^{2+}, \mathrm{Mg}^{2+}$, and $\mathrm{Mn}^{2+}$ caused slight activation on LipBT, while $\mathrm{Zn}^{2+}$ and $\mathrm{Fe}^{2+}$ showed strong inhibitory effect on the enzyme (Table 5). It was reported that $\mathrm{Ca}^{2+}$ increased the thermal stability of lipase in Chromohalobacter japonicas BK-AB18 [28]. As $\mathrm{Ca}^{2+}$ helps in the formation of disulfide bond, it is possible to increase the thermal stability of LipBT with the addition of this ion [29].

LipBT showed high stability in the presence of non-ionic surfactants (DMSO, Triton X-100, and Tween-80) (Table 6). SDS, an ionic surfactant, caused strong inhibitory effect on LipBT, in which the enzyme only retained $29 \%$ residual activity after $30 \mathrm{~min}$ of incubation in the presence of SDS. It is important to determine lipase stability towards various surfactants to assess whether or not the enzyme may be compatibly used as an additive in detergents [30].

In conclusion, we isolated, cloned, and co-expressed genes that encode for family I.2 lipase and its specific foldase from Burkholderia territorii GP3, a bacterium isolated from Mount Papandayan soil. The amino acid sequences of the lipase LipBT were closely related to those

Table 5. Effect of metal ions on LipBT activity after incubation for $30 \mathrm{~min}$ at $40^{\circ} \mathrm{C}, \mathrm{pH} 8.0$.

\begin{tabular}{lc}
\hline Metal ion & Relative activity $(\%)$ \\
\hline Control & 100.0 \\
$\mathrm{Ca}^{2+}$ & 120.6 \\
$\mathrm{Fe}^{2+}$ & 25.3 \\
$\mathrm{Mg}^{2+}$ & 114.9 \\
$\mathrm{Zn}^{2+}$ & 62.5 \\
$\mathrm{Mn}^{2+}$ & 103.7 \\
$\mathrm{Cu}^{2+}$ & 95.9 \\
\hline
\end{tabular}

Enzymatic activity was measured at $80^{\circ} \mathrm{C}, \mathrm{pH} 11.0$. The $100 \%$ relative activity represented an enzyme activity of $20.48 \mathrm{U} / \mathrm{mg}$.
Table 6. Effect of surfactants on LipBT activity after incubation for $30 \mathrm{~min}$ at $40^{\circ} \mathrm{C}, \mathrm{pH} 8.0$.

\begin{tabular}{lc}
\hline Surfactant & Relative activity $(\%)$ \\
\hline Control & 100.0 \\
Tween-80 & 103.8 \\
Triton X-100 & 111.9 \\
DMSO & 100.3 \\
SDS & 29.2 \\
\hline
\end{tabular}

Enzymatic activity was measured at $80^{\circ} \mathrm{C}, \mathrm{pH} 11.0$. The $100 \%$ relative activity represented an enzyme activity of $19.88 \mathrm{U} / \mathrm{mg}$.

of B. contaminans LTEB and B. cepacia ATCC 25416 with 97.0\% similarity. LipBT was unique compared to the other Burkholderia lipases, as it showed optimum activity at $80^{\circ} \mathrm{C}$ and $\mathrm{pH}$ 11.0. In general, LipBT may potentially be used as a catalyst in biodiesel and detergent formulation.

\section{Conflict of Interest}

The authors have no financial conflicts of interest to declare.

\section{References}

1. Hasan F, Shah AA, Hamed A. 2006. Industrial application of microbial lipases. Enzyme. Microbiol. Technol. 39: 235-251.

2. Yang J, Guo D, Yan Y. 2007. Cloning, expression and characterization of a novel thermal stable and short-chain alcohol tolerant lipase from Burkholderia cepacia strain G63. J. Mol. Catal. B. 45: 91-96.

3. Sebastian J, Muraleedharan C, Santhiagu A. 2016. A comparative study between chemical and enzymatic transesterification of high free fatty acid contained rubber seed oil for biodiesel production. Cog. Eng. 3: 1-12.

4. Wang X, Yu X, Xu Y. 2009. Homologous expression, purification and characterization of a novel high-alkaline and thermal stable lipase from Burkholderia cepacia ATCC 25416. Enzyme. Microb. Technol. 45: 94-102.

5. Alnoch RC, Stefanello AA, Martini VP, Richter JL, Mateo C, de Souza EM, et al. 2018. Co-expression, purification and characterization of the lipase and foldase of Burkholderia contaminans LTEB11. Int. J. Biol. Macromol. 116: 1222-1231.

6. Arpigny JE, Jaeger KE. 1999. Bacterial lipolytic enzymes: classification and properties. J. Biochem. 343(1): 177-183.

7. Quyen DT, Schmidt-Dannert C, Schmid RD. 1999. Highlevel formation of active Pseudomonas cepacia lipase atfter heterologous expression of the encoding gene and its modified foldase in Escherichia coli and rapid in vitro refolding. Appl. Environ. Microbiol. 65: 787-794. 
8. Martini VP, Glogauer A, Muller-Santos M, Iulek J, de Souza EM, Mitchell DA, et al. 2014. First co-expression of a lipase and its specific foldase obtained by metagenomics. Microb. Cell Fact. 13: 171

9. Marchesi JR, et al. 1998. Design and evaluation of useful bacterium-specific PCR primers that amplify genes coding for bacterial 16S rRNA. Appl. Environ. Microbiol. 64: 795-799.

10. Kearse M, Moir R, Wilson A, Stones-Havas S, Cheung M, Sturrock S, et al. 2012. Geneious Basic: an integrated and extendable desktop software platform for the organization and analysis of sequence data. Bioinformatics 28: 1647-1649.

11. Humphrey W, Dalke A, Schulten K. 1996. VMD: Visual Molecular Dynamics. J. Mol. Graph. 14: 33-38.

12. Sambrook J, Green RM. 2012. Molecular cloning: A Laboratory Manual 4th Edition. New York(US): Cold Spring Harbor.

13. Ceroni A, Passerini A, Vullo A, and Frasconi P. 2006. DISULFIND: a Disulfide Bonding State and Cysteine Connectivity Prediction Server. Nucleic Acids Res. 34: 177-181.

14. Waterhouse A, Bertoni M, Bienert S, Studer G, Tauriello G, Gumienny R, et al. 2018. SWISS-MODEL: homology modelling of protein structures and complexes. Nucleic Acids Res. 46: 296-303.

15. Uziela K, Hurtado DM, Shu N, Wallner B, Elofsson A. 2017. ProQ3D: Improved model quality assessments using Deep Learning. Bioinformatics 33: 1578-1580.

16. Kim YO, Khosasih V, Nam BH, Lee SJ, Suwanto A, Kim HK. 2012, Gene cloning and catalytic characterization of cold adapted lipase of Photobacterium sp. MA1-3 isolated from blood clam. J. Biosci. Bioeng. 114: 589-595.

17. Hamaki T, Suzuki M, Fudou R, Jojima Y, Kajiura T, Tabuchi A, et al. 2005. Isolation of novel bacteria and actinomycetes using soil-extract agar medium. J. Biosci. Bioeng. 99: 485-492.

18. Basu S, Bose C, Ojha N, Das N, Das J, Pal M, Khurana S. 2015. Evolution of bacterial and fungal growth media. Bioinformation 11: 182-184.

19. De Smet B, Mayo M, Peeters C, Zlosnik JE, Spilker T, Hird TJ, et al. 2015. Burkholderia stagnalis sp. nov. And Burkholderia territorii sp. nov., two novel Burkholderia cepacia complex species from environmental and human sources. Int. J. Syst. Evol. Microbiol. 65: 2265-71.

20. Bane SE, Velasquez JE, Robinson AS. 2006. Expression and purification of milligram levels of inactive G-protein coupled receptors in E. coli. Protein Expr. Purif. 52: 348-355.

21. Arifin, Ranlym A, Kim SJ, Yim JH, Suwanto A, Kim HK. 2013. Isolation and biochemical characterization of Bacillus pumilus lipases from the Antartic. J. Microbiol. Biotechnol. 23: 661-667.

22. Takeda Y, Aono R, Doukyu N. 2006. Purification, characterization, and molecular cloning of organic-solventtolerant cholesterol esterase from cyclohexanetolerant Burkholderia cepacia strain ST-200. Extremophiles 10: 269-277.

23. Gupta R, Gupta N, Rathi P. 2004. Bacterial lipases: an overview of production, purification, and biochemical properties. Appl. Microbiol. Biotechnol. 64: 763-781.

24. Liu T, Wang Y, Luo X, Li J, Reed SA, Xiao H, et al. 2016. Enhancing protein stability with extended disulfide bonds. Proc. Natl. Acad. Sci. USA 113: 5910-5915.

25. Svendsen A, Borch K, BarfoedM, Nielsen TB, Gormsen E, Patkar SA. 1995. Biochemical properties of cloned lipases fromthe Pseudomonas family. Biochim. Biophys. Acta 1259: 9-17.

26. Seitz EW. 1974. Industrial applications of microbial lipases-a review. J. Am. Oil. Chem. Soc. 51: 12-16.

27. Casas-Godoy L, Duquesne S, Bordes F, Sandoval G, Marty A. 2012. Lipases and Phospholipases: Methods and Protocols, pp. 411. Springer Science Business Media, New York.

28. Hertadi R, Widhyastuti H. 2015. Effect of Ca2+ to the activity and stability of lipase isolated from Chromohalobacter japonicas BK-AB18. Procedia Chem. 16: 306-313.

29. Liebeton K, Zacharias A, Jaeger KE. 2001. Disulfide bound in Pseudomonas aeruginosa lipase stabilizes the structure but is not required for inetraction with its foldase. J. Bacteriol. 183: $597-603$.

30. Cherif S, Mnif S, Hadrich F, Abdelkafi S, Sayadi S. 2011. A new highly alkaline lipase: an ideal choice for application in detergent formulations. Lipids Health Dis. 10: 221. 